\title{
AN EXPERIMENTAL STUDY OF EMISSION AND COMBUSTION CHARACTERISTICS OF MARINE DIESEL ENGINE IN CASE OF CYLINDER VALVES LEAKAGE
}

Jerzy Kowalski, Ph.D.

Gdynia Maritime University, Poland

\begin{abstract}
Presented paper shows the results of the laboratory tests on the relationship between throttling of both air intake duct and exhaust gas duct and a gaseous emission from the marine engine. The object of research is a laboratory, four-stroke, DI diesel engine, operated at loads from $50 \mathrm{~kW}$ to $250 \mathrm{~kW}$ at a constant speed equal to $750 \mathrm{rpm}$. During the laboratory tests over 50 parameters of the engine were measured with its technical condition recognized as a „working properly” and with simulated leakage of both air intake valve and exhaust gas valve on the second cylinder. The results of this laboratory research confirm that the leakage of cylinder valves causes no significant changes of the thermodynamic parameters of the engine. Simulated leakages through the inlet and exhaust valve caused a significant increase in fuel consumption of the engine. Valve leakages cause an increase of the exhaust gas temperature behind the cylinder with leakage and behind other cylinders. The exhaust gas temperature increase is relatively small and clearly visible only at low loads of the engine. The increase of the temperature and pressure of the charging air behind the intercooler were observed too. Charging air temperature is significantly higher during the engine operation with inlet valve leakage. The study results show significant increases of the $\mathrm{CO}, \mathrm{NOx}$ and $\mathrm{CO}_{2}$ emission for all the mentioned malfunctions. The conclusion is that the results of measurements of the composition of the exhaust gas may contain valuable diagnostic information about the technical condition of the air intake duct and the exhaust gas duct of the marine engine.
\end{abstract}

Keywords: marine diesel engine, exhaust gas composition, emission, exhaust gas valve leakage, inlet valve leakage

\section{INTRODUCTION}

In classic technical solution of a ship engine room a few diesel engines are installed. One or more engines are installed as a main propulsion. Usually there are low-speed, twostroke diesel engines operating with fixed pitch propeller [1], or medium - speed, 4-stroke diesel engines operating at a constant speed with variable pitch propeller. Moreover, there are two or more power generators and one emergency power generator in the ship engine room. The power generator usually contains medium-speed, 4-stroke diesel engine operating at a constant speed.

One of the crucial tasks of the ship's crew is keeping marine engines in proper technical condition. This task is especially important for the ship safety, but also because of reduction of the operating costs and of the negative impacts on the marine environment. The ship's crew cannot allow the main propulsion engine to emergency stop in case of unfavorable weather conditions. It should also be noted that the engine with nominal power equal to $10 \mathrm{MW}$ consumes about 2 tons of fuel, emitting large quantities of toxic compounds into the atmosphere. Each engine failure causes an increase of fuel consumption and of toxic compounds emissions. For the reasons the ship's crew controls technical parameters of engines and tries to predict their condition. Due to the specification of the onboard operation, ship engines maintenance must be planned well ahead. The main propulsion engine stop for the maintenance can be made only under certain conditions. For example, according to ISGOTT regulation [2], an oil tanker staying at marine terminal must be prepared to an immediate departure in case of danger from land (e. g. fire, terrorist attack). Planned engines maintenance must also consider the supply of spare parts.

For these reasons the correct operation of main propulsion engine boils down to the continuous diagnostics of engine technical condition. Standard approach to the diagnosis of the technical elements of engine cylinders and therefore the combustion process is the observation of the exhaust gas temperature behind individual cylinders of the engine and observation of the turbocharger operating parameters. In cases of significant temperature variations between cylinders or exceeding the threshold values (which is usually only during significant failures and/or the engine operating at the load close to the nominal) additional measurements of the cylinder combustion pressure are made. This method is ineffective. Even small changes of the engine operating 
parameters can lead to a significant increase of emission levels and the fuel consumption. It should be remembered that the analysis of the combustion pressure in marine engine cylinders is considerably impeded. In the presented case the determination of the crankshaft angular position, based on compression pressure characteristics in engine cylinder is usually impossible. The reason of this is the ignition of the fuel before the TDC (Top Dead Centre) engine crankshaft position. According to the research results presented in [3], TDC determination error of one degree of crank angular position leads on average to $7-10 \%$ error of mean in-cylinder pressure. The distance between the cylinder chamber and the place of installation of combustion pressure sensor is also a problem. According to the research results presented in [4], this distance can result in the displacement of the characteristics of combustion pressure in the cylinder of up to 6 - 7 degrees of the angular position of the crankshaft. The presented conditions cause the quality and quantity of diagnostic signals to limit significantly during the onboard operation, which in consequence leads to a significant increase of the engine maintenance costs.

International Maritime Organization introduced a legislation imposing on the ship owners to control and reduce nitric oxides emission from the engines with a nominal power over $130 \mathrm{~kW}$ [5] installed onboard after 2001. These regulations, among others, allow to measure toxic compounds emissions. This provides an opportunity to obtain additional information about the engine condition. The author believes that the composition of the exhaust gases can bring diagnostic signals of the engine condition during onboard operation.

Construction of diesel engines with mechanically controlled fuel systems were intensively studied in 20th century. Unfortunately, most publications were focused on the aspects related to improving the energy efficiency. Less attention was paid to reduction of the toxic compounds emission. Only a few new experimental works focusing on the emission characteristics of marine diesel engines are available.

Sarvi et al. [6], [7], [8] present emission characteristics of a large medium-speed diesel engine with parameters similar to those of marine engines. Desantes et al. [9], [10] show influence of fuel injection characteristics on emission characteristics and parameters of combustion in one cylinder engine. Weiser, in his doctor's thesis [11] , presents results of direct measurements on 9- cylinder, medium-speed engine. Works about comparing the emission characteristics of diesel engines with direct and indirect fuel injection [12], different types of fuels [12], injection strategies [13] - [16], and nozzle geometries [17] , are also available. The experimental investigations of diesel combustion with water emulsion [18], [19] and different fuel bio-components [20] - [30] and much frequently are presented.

This paper presents the results of the experimental studies on the effects of the cylinder valves leakage (both at air inlet and exhaust outlet) on the composition of the exhaust gas.

\section{LABORATORY STAND}

The object of research is a three-cylinder, four-stroke, turbocharged, laboratory engine with mechanically controlled fuel pumps, inlet and exhaust valves. The fuelling system of the engine consists of Bosch fuel pumps and multi-hole fuel nozzles. The engine was loaded by an electrically-connected, water resistance generator. During the tests the engine was fuelled by diesel oil and operated at a constant speed equal to $750 \mathrm{rpm}$. This type of engine is commonly used onboard as a power generator or a main propulsion system with variable pitch propeller [1]. The load and speed of the engine, speed of the turbocharger and parameters of cooling, fuelling, lubricating, and air exchange systems, were measured. The composition of exhaust gas was also recorded by using an electrochemical gas analyser with infrared carbon dioxide sensor. Pressure, temperature and humidity of air were also recorded by laboratory equipment. All the mentioned results were recorded with a 1 - second sampling time. Injection pressures and pressures of the combustion in all cylinders of the engine were also collected with a resolution of 0,5 degree of the engine shaft rotation angle. The scheme of the laboratory stand is presented in [1] and the engine parameters are given in Tab.1.

Tab.1. Parameters of the test engine

\begin{tabular}{|l|r|r|}
\hline \multicolumn{1}{|c|}{ Parameter } & Value & Unit \\
\hline Max. electric power & 250 & $\mathrm{~kW}$ \\
\hline Rotational speed & 750 & $\mathrm{rpm}$ \\
\hline Number of cylinders & 3 & - \\
\hline Cylinder diameter & 250 & $\mathrm{~mm}$ \\
\hline Stroke & 300 & $\mathrm{~mm}$ \\
\hline Compression ratio & 12,7 & - \\
\hline Number of inlet valves per cylinder & 1 & - \\
\hline $\begin{array}{l}\text { Number of exhaust valves per } \\
\text { cylinder }\end{array}$ & 1 & - \\
\hline Valves diameter & 98 & $\mathrm{~mm}$ \\
\hline Valves shift & 24 & $\mathrm{~mm}$ \\
\hline
\end{tabular}

The experimental study consists of 4 stages of 3 observations each with simulations of different malfunctions of both air inlet valve and exhaust valve in second cylinder of the engine. During each start of the observation, the engine was loaded to a maximum load equal to $250 \mathrm{~kW}$, measured as the electric power of the generator. After stabilizing the temperature of the exhaust gas behind the turbine, the engine operating parameters were recorded for 3 to 5 minutes. After that, the load of the engine was decreased by $10 \mathrm{~kW}$ and, after stabilizing the temperature of the exhaust gas behind the turbine, the engine operating parameters were recorded again. Observation was continued with loads up to $50 \mathrm{~kW}$. The engine did not work with a load of $190 \mathrm{~kW}$ due to resonance vibrations.

The stages of the experiment were set as follows: 1st stage - during the operation of the engine assumed as "working properly", 
- $\quad$ 2nd stage - during the operation of the engine with a small simulated leakage of the air inlet valve, 3rd stage - during the operation of the engine with a small simulated leakage of the exhaust valve, 4th stage - during the operation of the engine with a large simulated leakage of the exhaust valve.

The mentioned simulations of valves leakage were obtained by drilling holes in the valve, according to the scheme presented in Fig.2. A small leakage was simulated by drilling one hole of $1 \mathrm{~mm}$ diameter and a large leakage was simulated by drilling four holes of $2 \mathrm{~mm}$ diameter.

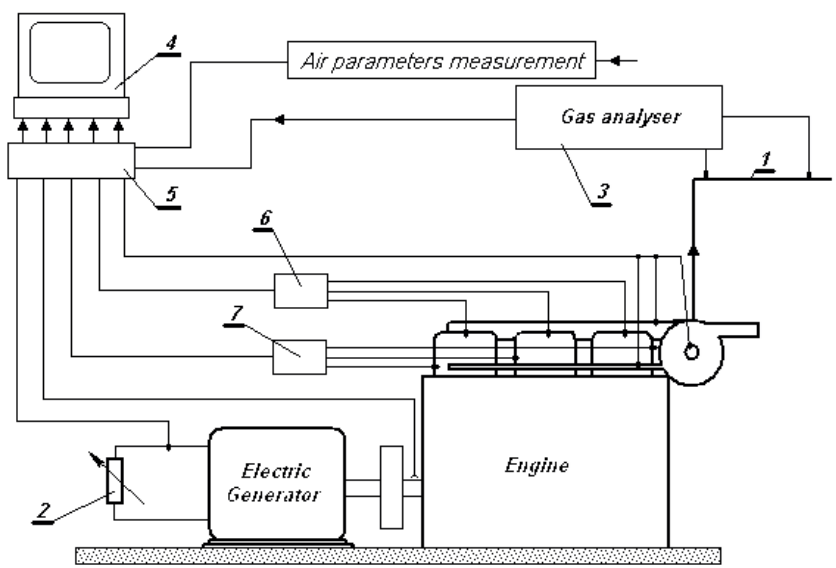

Fig.1. The laboratory stand scheme. 1 - exhaust duct, 2 - water resistance, 3 - gas analyzer, 4 - computer, 5 - A/C converter, 6 - combustion pressure indicator, 7 - injection pressure indicator

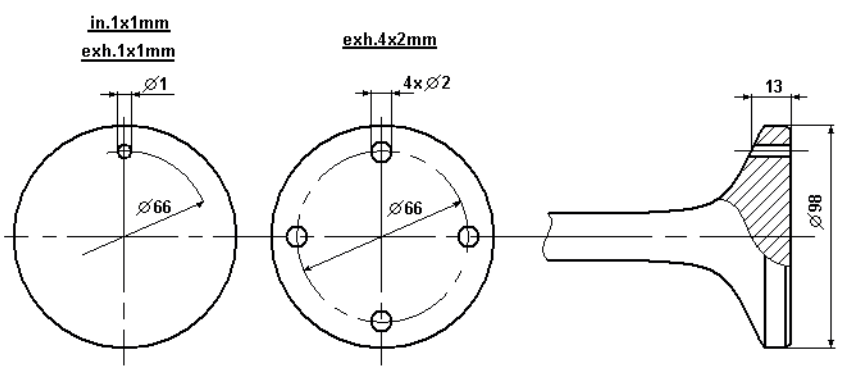

Fig.2. Scheme of the valve leakage simulation

\section{RESULTS AND DISCUSSION}

Figures from 4. to 6. present average changes of measured and calculated parameters of the engine with simulated malfunctions in relation to the parameters of the operation of the engine recognized as "working properly" (Fig.3).

\section{INLET VALVE LEAKAGE}

The air intake valve leakage was simulated by drilling one hole in the valve with a diameter of $1 \mathrm{~mm}$. The location of the hole was selected in a way to separate the surfaces of the valve seat from leaking gas into cylinder.

The air intake valve leakage in the second engine cylinder causes penetration of the gas mixture to the air intake duct. The mixture of gases in the cylinder has a higher temperature, and therefore, according to the results presented in Fig. $4 \mathrm{a}$ and Fig. 4 b, the mentioned malfunction causes an increase of the air pressure and temperature behind the intercooler. The results of the measurements for the engine assumed as "working properly", presented in Fig.3a, show that the increase of the engine load leads to an increase of the air pressure behind the intercooler at a stable temperature. The air intake valve leakage causes an increase of the air temperature and the air pressure at low loads of engine operation. The result of the increase of thermodynamic parameters of air in the air intake duct is an increase of the temperature and pressure of air entering also other engine cylinders. These changes, however, do not change the amount of supplied air in relation to fuel consumption in all considered engine loads. This conclusion results from the lack of oxygen content changes in the exhaust gas for all considered loads of the engine (the result were not presented in this paper). Therefore, the increase of air pressure is compensated in the object of research by the temperature rise, and thus the amount of air supplied to the cylinders increases proportionally to fuel consumption increase. The change of temperature and pressure of the air behind the intercooler results in a deterioration of the combustion process in all engine cylinders. Fig.5c shows

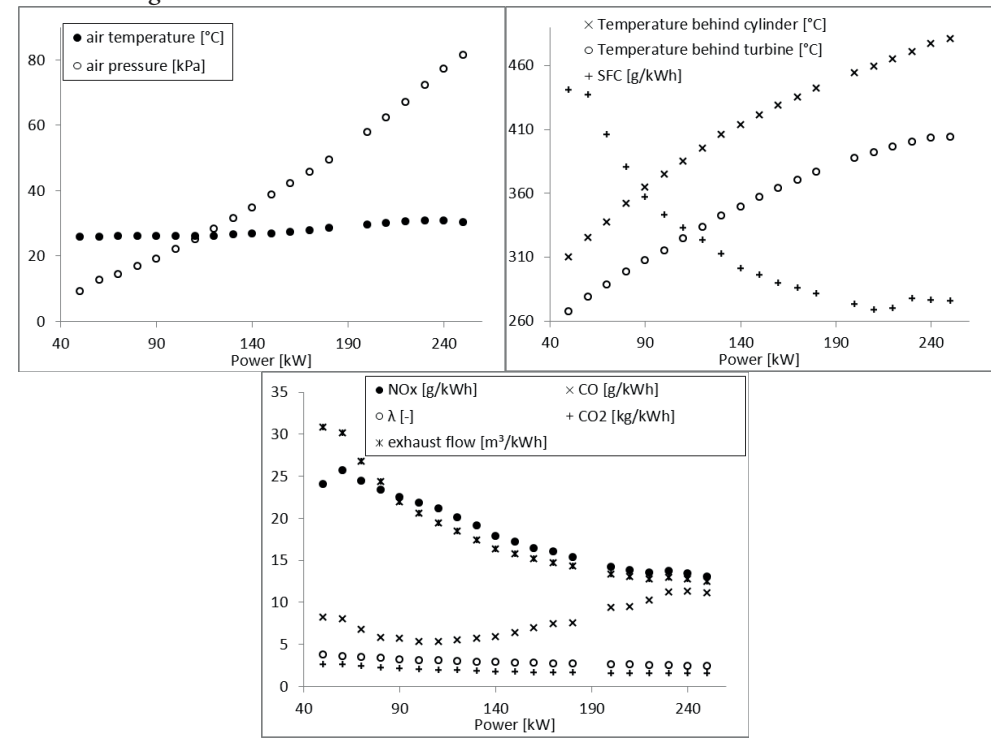

Fig.3. Parameters of the engine assumed "working properly" 

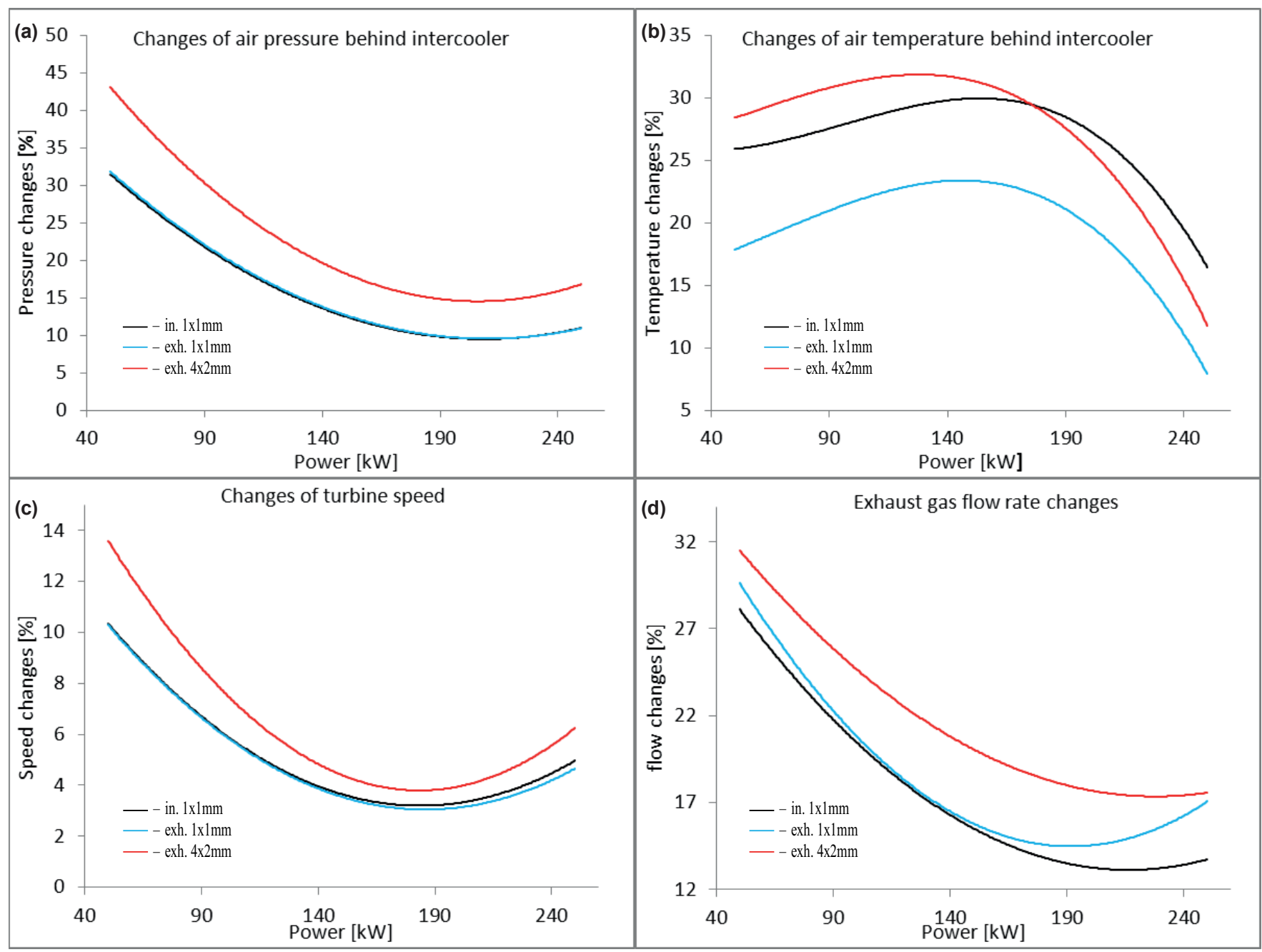

Fig.4. Changes of the air parameters in front of the cylinders, changes of the turbine speed and the exhaust gas flow rate

changes of the specific fuel consumption (SFC) with changes of the engine loads. According to the presented results, the $10-27 \%$ increase in fuel consumption follows, clearly visible especially at low loads engine operation. The increase of the fuel consumption also increases amounts of the carbon dioxide $\left(\mathrm{CO}_{2}\right)$ emission, which was presented in Fig.6d. The characteristics of carbon monoxide (CO) emission indicate the deterioration of the combustion process. According to Fig.6c, the air intake valve leakage causes about $60 \%$ increase in amounts of $\mathrm{CO}$ emission in relation to those from the engine assumed "working properly", presented in Fig.3c. The deterioration of the combustion process causes the increase of the exhaust gas temperature behind the engine cylinders. According to the results presented in Fig.5a and Fig.5b, changes of the exhaust gas temperature behind cylinders are similar for all engine cylinders. Fig.5d shows the change in the exhaust gas temperature measured at the exhaust gas duct behind the turbocharger. According to the presented results the air intake valve leakage causes a relatively small increase of temperature.

As a result, an increase in the turbocharger speed occurs. According to the results in Fig. $4 \mathrm{c}$, the increase of the rotational speed of the turbocharger is so small that it may go unnoticed during the onboard operation. The change in the turbocharger and the engine cooperation as well as the mentioned conditions cause an increase of the volumetric exhaust gas flow rate. Fig. 4 d presents changes of the exhaust gas flow rate according to the engine load conditions. A volumetric exhaust gas flow rate was obtained by calculation with the use of the carbon balance method, in accordance with ISO 8178 standard regulation [31]. According to the presented results, the $10-28 \%$ increase of volumetric exhaust gas flow rate followed. The largest changes of the presented parameters were observed for low engine loads. The reason for this is the constant size of the simulated valve leakage. The air inlet valve leakage causes a leakage of the gaseous mixture from a cylinder, which, in relation to combusted mixture mass in the cylinder, increases at low engine load operation.

Fig.6a and Fig.6b present changes in values of both fraction and emission of nitric oxides $\left(\mathrm{NO}_{\mathrm{x}}\right)$ in relation to the operation of the engine assumed "working properly" for all considered loads of the engine. According to the presented results, the air intake valve leakage causes a noticeable decrease of the $\mathrm{NO}_{\mathrm{x}}$ fraction in exhaust gas. The probable reason for this is a decrease of the combustion temperature in the leaky cylinder. However, this thesis has not been proved in this research. It should be noted that the deterioration of the combustion process in the leaky cylinder and the changes 

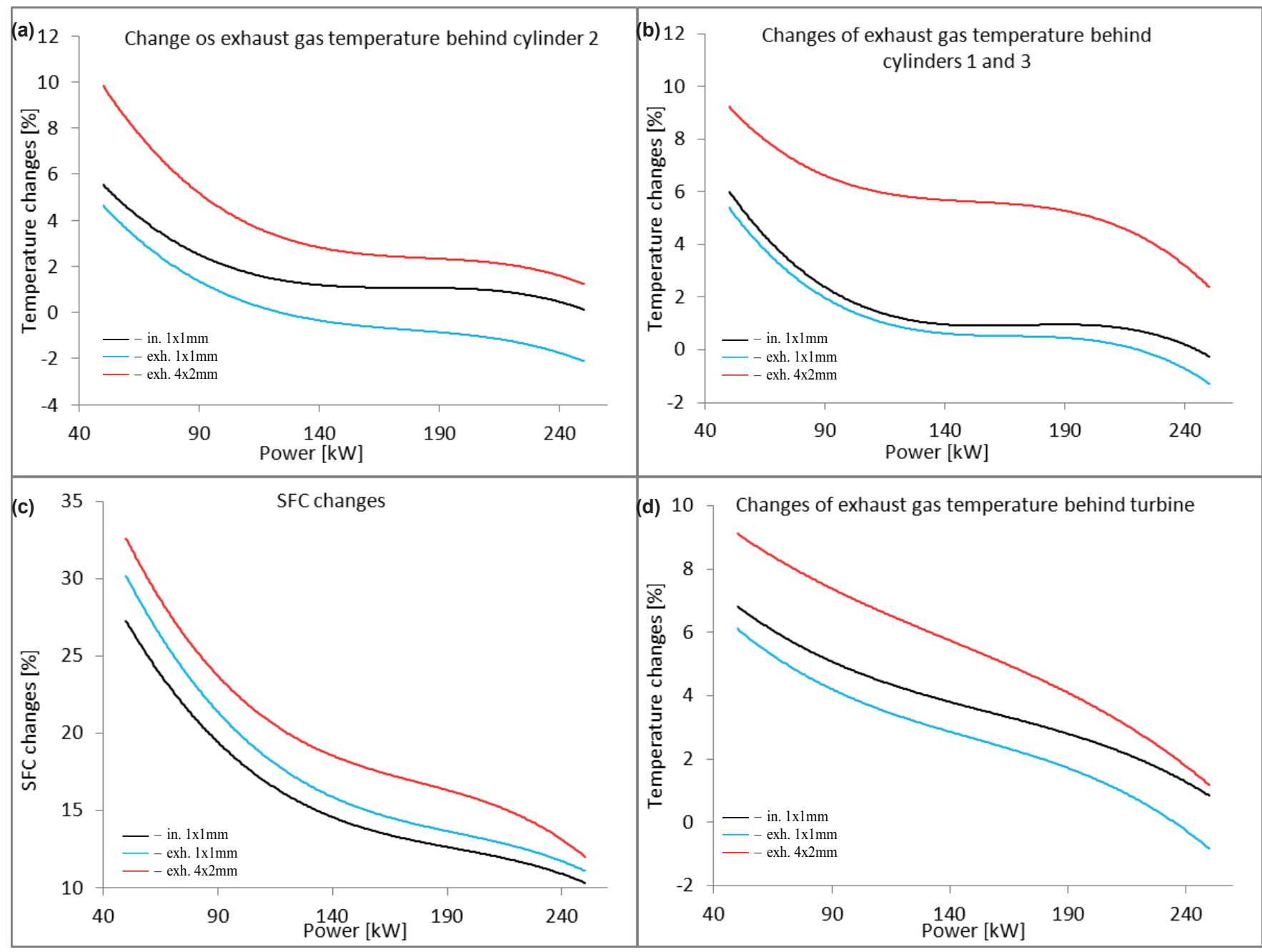

Fig.5. Changes of exhaust gas parameters and specific fuel consumption in relation to engine assumed "working properly"

in the engine and the turbocharger cooperation result in the fuel consumption increase and the increase of the exhaust gas volume. This implies an increase of $\mathrm{NO}_{x}$ emission, despite a decrease of $\mathrm{NO}_{x}$ fraction in exhaust gas. Changes of $\mathrm{NO}_{\mathrm{x}}$ emission in relation to $\mathrm{NO}_{x}$ emission from the engine assumed "working properly" are presented in Fig.6b.

According to the presented results, a relatively small leakage of air intake valve can cause significant changes in the emission of $\mathrm{CO}_{2}, \mathrm{CO}$ and $\mathrm{NO}_{\mathrm{x}}$ and the fuel consumption increase.

\section{EXHAUST VALVE LEAKAGE}

Exhaust valve leakage is a very common malfunction. It is caused by the damage of the valve seat due to hot and corrosive exhaust gases.

In this experiment the exhaust valve leakage was simulated by drilling holes in the valve as shown in Fig.2. Two leakages were simulated:

- a small leakage, which consists of one hole with a diameter of $1 \mathrm{~mm}$, its cross - section area corresponding to leakage of $0,1 \mathrm{~mm}$ thickness of valve seat with angle equal to 10 degrees,
- a large leakage, which consists of four holes with diameters of $2 \mathrm{~mm}$, which corresponds to leakage of $0.3 \mathrm{~mm}$ thickness of the valve seat with angle equal to 55 degrees.

The exhaust valve leakage causes the penetration of the gas mixture to the exhaust gas duct during the combustion process in the cylinder. The result is a reduction of the maximum combustion pressure in the cylinder and the increase of the exhaust gas temperature behind the cylinder. According to Fig.5a and Fig.5b, the increase of the exhaust gas leakage causes the increase of the exhaust gas temperature behind a damaged cylinder, but also for cylinders without leaks. The presented increase of the exhaust gas temperature is relatively low and clearly visible only at low loads of the engine. Accordingly, the observation of this parameter allows to detect a large leakage of the exhaust valves only. It should be noted that simulated leakage will not initiate the automatic alarm systems. A leakage of the combustible mixture to the exhaust gas duct causes a deterioration of the engine efficiency. According to Fig.5c, the simulated malfunctions producing even small changes of the exhaust gas temperature behind cylinders, cause a large increase of SFC, reaching up to $30 \%$ at low engine loads operation. Similarly to the case 


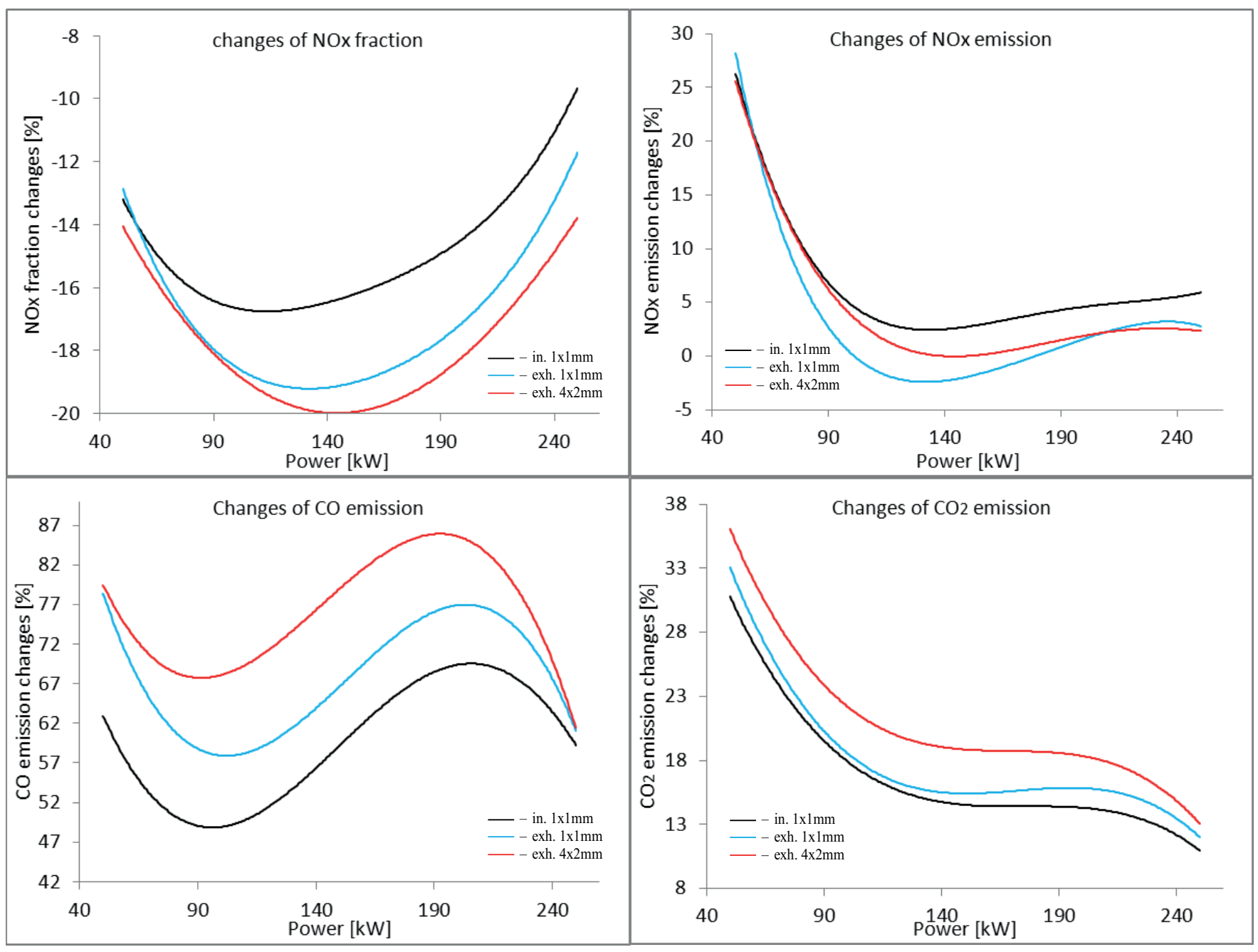

Fig.6. Exhaust gas composition changes

of the air intake valve leakage, the amount of air in relation to the amount of burned fuel undergoes no visible change (this result is not presented in this paper). Leakages of the gaseous mixture into the exhaust gas duct and the increase of the exhaust gas temperature behind all cylinders cause the increase of the rotational speed of the turbocharger. Fig. $4 \mathrm{c}$ presents the turbocharger speed changes caused by the simulated malfunctions. The mentioned results are compared to the parameters of the operation of the engine assumed as "working properly", presented in Fig.3b. According to the presented results, the increase of the leakage causes the increase of the turbocharger speed. Volumetric flow rate of the exhaust gas, calculated according to the mentioned algorithm, rises with the increase of the valve leakage. As reported by the results presented in Fig.4d, the exhaust valve leakage in one cylinder causes even a $30 \%$ increase of the volumetric exhaust gas flow rate at low engine loads. This result is also the effect of the exhaust gas temperature increase behind the turbine, which is presented in Fig. 5 d.

Exhaust valve leakage in one of the engine cylinders causes an increase of both temperature and pressure of the charging air in front of the cylinders. According to Fig. $4 \mathrm{a}$ and Fig. $4 \mathrm{~b}$, the characteristics of the charging air temperature and pressure are qualitatively similar to the previously discussed inlet valve leakage. Although the effect of both the discussed valve malfunctions is similar, the genesis of these phenomena is different. In the case of the exhaust valve leakage the increase of the charging air pressure and temperature in front of the engine cylinders is a result of the increased compressor efficiency, caused by the increase of turbine speed. The inlet valve leakage causes, apart from the mentioned increase of the compressor efficiency, the additional increase of the charging air temperature as a result of the mixing of air and leaking combustible mixture from the cylinder. The result of this is that the same size of a leakage at the inlet and exhaust valve causes the same increase of the charging air pressure (Fig.4a), but the charging air temperature is significantly higher during the engine operation with inlet valve leakage (Fig.4b).

Increased fuel consumption of the engine is the direct cause of the $\mathrm{CO}_{2}$ emission increase. According to the measurement results presented in Fig.6d, the increase of the exhaust valve leakage causes an increase of the $\mathrm{CO}_{2}$ emission, especially at low engine loads operation. As mentioned earlier, the exhaust valve leakage causes the decrease of the maximum combustion pressure and the deterioration of the combustion process. The result of this is a large increase of 
the $\mathrm{CO}$ emission, which rises with an increase of the exhaust valve leakage. Changes of the $\mathrm{CO}$ emission in all considered loads of the engine are presented in Fig.6c. As for the case of the inlet valve leakage, the described malfunction reduces the $\mathrm{NO}_{\mathrm{x}}$ fraction in the exhaust gas. In Fig.6a a drop of the $\mathrm{NO}_{\mathrm{x}}$ fraction together with the increase of the leakage is also observed. This is caused by the combustion pressure decrease. There is a probability that the temperature of the combustion process also decreased (thus implicitly indicated also the increase in the $\mathrm{CO}$ emission), but it was not clearly confirmed by the measurement results. The correlation of changes in the $\mathrm{NO}_{\mathrm{x}}$ fraction and the exhaust gas flow causes, at low loads of the engine, a significant increase of the $\mathrm{NO}_{\mathrm{x}}$ emission. The increase of load of the engine operating with the exhaust valve leakage in one cylinder, results in a reduction of the $\mathrm{NO}_{\mathrm{x}}$ emissions in comparison to the values observed for the engine assumed as "working properly". It should be noted that the increase of the engine load rises the amount of combusted mixture in the cylinder, which, at the same cross-section area of valve leakage, provides a relative decrease of leakage through the leaking valve. The mentioned leakage depends also on the pressure difference in front and behind the leaking valve. According to the obtained results the simulated leakages are too small to increase the combusted mixture amount (consequently the load) to such an extent as to cause a proportional increase of the leakage.

\section{CONCLUSIONS}

This paper presents the results of laboratory tests carried out on the four-stroke diesel engine for marine applications. The study consisted of determining the impact of the leakage of both the air intake valve and the exhaust gas valve on the engine operating parameters, including the composition of exhaust gas.

The obtained results of the measurements allow to formulate the following conclusions:

1. The simulated leakages in the inlet and the exhaust valve caused a significant increase in the fuel consumption of the engine. It was also observed that the amount of air delivered to the engine cylinders increases in proportion to the increase of the fuel consumption.

2. The valve leakages cause an increase of the exhaust gas temperature behind the cylinder with a leakage and behind the other cylinders. The presented exhaust gas temperature increase is relatively small and clearly visible only at low loads of the engine. Therefore, the observation of this parameter allows to detect only large leakages of the exhaust valves.

3. The valve leakages taken into account in this experiment cause an increase of temperature and pressure of charging air behind the intercooler. This increase is caused by the risen efficiency of the turbocharger. In case of the inlet valve leakage, an additional increase of temperature was observed, caused by a gas leakage into the air intake duct. Charging air temperature is significantly higher during the engine operation with inlet valve leakage in one cylinder.

4. In all the simulated malfunctions the deterioration of the combustion process in leaky cylinder and the change of the co-operation between the engine and the turbocharger were observed. Relatively small valve leakages caused significant changes in $\mathrm{CO}_{2}, \mathrm{CO}$ and $\mathrm{NO}_{\mathrm{x}}$ emissions.

5. The largest changes of the mechanical and thermodynamic parameters of the engine and gaseous emissions were observed for low engine loads. The reason for this is the constant size of the simulated valve leakage in all the considered engine loads. The simulated leakages caused an amount of gaseous mixture to flow out from the cylinder, which, in relation to the mass of the mixture in the cylinder, is larger at low loads of engine operation.

\section{NOMENCLATURE}

$\mathrm{CO}$ - carbon monoxide

$\mathrm{CO}_{2}$ - carbon dioxide

ISGOTT - International Safety Guide for Oil Tankers and Terminals

$\mathrm{NO}_{\mathrm{x}}$ - nitric oxides

SFC - Specific fuel consumption $[\mathrm{g} / \mathrm{kWh}]$

TDC - top dead centre of crankshaft position

\section{ACKNOWLEDGMENTS}

The project was supported by the National Science Centre in Poland, granted on the basis of decision No. DEC-2011/01/D/ ST8/07142.

\section{BIBLIOGRAPHY}

1. J. Carlton: Marine Propellers and Propulsion. Third Ed., Elsevier Ltd., 2012.

2. International Safety Guide for Oil Tankers and Terminals. ICS, OCIMF, IAPH, 2006.

3. R. Pawletko, S. Polanowski: Research of the influence of marine diesel engine Sulzer AL 25/30 load on the TDC position on the indication graph, Journal of KONES , Powertrain and Transport 17,2010 , pp. 361 - 368.

4. R. Pawletko, S. Polanowski : Influence of gas channels of medium speed marine engines on the accuracy of determination of diagnostic parameters based on the indicator diagrams. Journal of Polish CIMAC 7,2012, pp. 139 - 146.

5. Marine Engine IMO Tier II Programme 2013 
6. A. Sarvi, C. J. Fogelholm, R. Zevenhoven : Emissions from large-scale medium-speed diesel engines: 1 . Influence of engine operation mode and turbocharger.Fuel processing technology 89 , 2008, pp. $510-519$.

7. A. Sarvi, C. J. Fogelholm, R. Zevenhoven: Emissions from large-scale medium-speed diesel engines: 2. Influence of fuel type and operating mode. Fuel processing technology 89,2008 , pp. $520-527$.

8. A. Sarvi, R. Zevenhoven : Large-scale diesel engine emission control parameters. Energy 35 , 2010, pp. 1139 1145.

9. J.M. Desantes, J. Benajes, S. Molina, C.A. Gonzalez : The modification of the fuel injection rate in heavy-duty diesel engines. Part 1: Effects on engine performance and emissions. Applied Thermal Engineering 24, 2004, pp. 2701-2714.

10. J.M. Desantes, J. Benajes, S. Molina, C.A. Gonzalez: The modification of the fuel injection rate in heavy-duty diesel engines. Part 2: Effects on combustion. Applied Thermal Engineering 24 ,2004, pp. 2715-2726.

11. G.A. Weiser: Modeling of Combustion and Nitric Oxide Formation for Medium-Speed DI Diesel Engines: A Comparative Evaluation of Zero- and Three-Dimensional Approaches. Doctor's Thesis, Swiss Federal Institute of Technology, Zurich, 2001.

12. J. Huang, L. Lin, Y. Wang, J. Qin, A. P. Roskilly, L. Li, T. Ouyang, Y. Yu : Experimental study of the performance and emission characteristics of diesel engine using direct and indirect injection systems and different fuels. Fuel Processing Technology 92 , 2011, pp. 1380-1386.

13. K. Verbiezen, A.J. Donkerbroek, R.J.H. Klein-Douwel, A.P. van Vliet, P.J.M. Frijters, X.L.J. Seykens, R.S.G. Baert, W.L. Meerts, N.J. Dam, J.J. ter Meulen: Diesel combustion: In-cylinder NO concentrations in relation to injection timing. Combustion and Flame 151 , 2007, pp. 333-346.

14. E. Buyukkaya, M. Cerit: Experimental study of NOx emissions and injection timing of a low heat rejection diesel engine. International Journal of Thermal Sciences 47 , 2008, pp.1096-1106.

15. T. Thurnheer, D. Edenhauser, P. Soltic, D. Schreiber, P. Kirchen, A. Sankowski : Experimental investigation on different injection strategies in a heavy-duty diesel engine: Emissions and loss analysis. Energy Conversion and Management 52 , 2011, pp. 457-467.

16. A. Parlak, H. Yasar, C. Hasimoglu, A. Kolip: The effects of injection timing on NOx emissions of a low heat rejection indirect diesel injection engine. Applied Thermal Engineering 25, 2005, pp. 3042-3052.
17. R. Payri, F.J. Salvador, J. Gimeno, L.D. Zapata: Diesel nozzle geometry influence on spray liquid-phase fuel penetration in evaporative conditions. Fuel 87, 2008, pp. $1165-1176$.

18. M. Ebna Alam Fahd, Yang Wenming, P.S. Lee, S.K. Chou, Christopher R. Yap: Experimental investigation of the performance and emission characteristics of direct injection diesel engine by water emulsion diesel under varying engine load condition. Applied Energy 102, 2013, pp. 1042-1049.

19. W.M. Yang, H. An, S.K. Chou, S. Vedharaji, R. Vallinagam, M. Balaji, F.E.A. Mohammad, K.J.E. Chua: Emulsion fuel with novel nano-organic additives for diesel engine application. Fuel 104 ,2013, pp. 726-731.

20. A. Kumar Agarwal, A. Dhar: Experimental investigations of performance, emission and combustion characteristics of Karanja oil blends fuelled DICI engine. Renewable Energy 52, 2013, pp. $283-291$.

21. A.K. Hossain, M. Ouadi, S.U. Siddiqui, Y. Yang, J. Brammer, A. Hornung, M. Kay, P.A. Davies: Experimental investigation of performance, emission and combustion characteristics of an indirect injection multi-cylinder CI engine fuelled by blends of de-inking sludge pyrolysis oil with biodiesel. Fuel 105, 2013, pp. 135-142.

22. D.C. Rakopoulos : Combustion and emissions of cottonseed oil and its bio-diesel in blends with either n-butanol or diethyl ether in HSDI diesel engine. Fuel 105, 2013, pp. 603-613.

23. S. Saravanan, G. Nagarajan, S. Sampath : Combined effect of injection timing, EGR and injection pressure in NOx control of a stationary diesel engine fuelled with crude rice bran oil methyl ester. Fuel 104, 2013, pp. 409-416.

24. P. Behera, S. Murugan: Combustion, performance and emission parameters of used transformer oil and its diesel blends in a DI diesel engine. Fuel 104, 2013, pp. 147-154.

25. B. İşcan, H. Aydın : Improving the usability of vegetable oils as a fuel in a low heat rejection diesel engine. Fuel Processing Technology 98 , 2012, pp. 59-64.

26. S. Altun, H. Bulut, C. Oner: The comparison of engine performance and exhaust emission characteristics of sesame oil-diesel fuel mixture with diesel fuel in a direct injection diesel engine. Renewable Energy 33 , 2008, pp. 1791-1795.

27. Ch. Yao, C.S. Cheung, Ch. Cheng, Y. Wang, T.L. Chan, S.C. Lee: Effect of Diesel/methanol compound combustion on Diesel engine combustion and emissions. Energy Conversion and Management 49, 2008, pp. 1696-1704. 
28. H. Aydin, C. Ilkılıç : Effect of ethanol blending with biodiesel on engine performance and exhaust emissions in a CI engine. Applied Thermal Engineering 30 , 2010, pp. 1199-1204.

29. J. Huang, Y. Wang, J. Qin, A. P. Roskilly: Comparative study of performance and emissions of a diesel engine using Chinese pistache and jatropha biodiesel. Fuel Processing Technology 91 ,2010, pp. 1761-1767.

30. Y.D. Wang, T. Al-Shemmeri, P. Eames, J. McMullan, N. Hewitt, Y. Huang, S. Rezvani: An experimental investigation of the performance and gaseous exhaust emissions of a diesel engine using blends of a vegetable oil. Applied Thermal Engineering 26, 2006, pp. 1684-1691.

31. International Organization of Standardization : ISO 8178 regulation.
CONTACT WIHT AUTHOR

\author{
Jerzy Kowalski \\ Department of Engineering Sciences \\ Gdynia Maritime University \\ Morska 81-87 Str. \\ 81-225 Gdynia \\ Poland \\ tel.: +48586901331 \\ fax: +48586901399 \\ e-mail: jerzy95@am.gdynia.pl
}

